\title{
Avaliação da intensidade de amargor e do seu princípio ativo em cervejas de diferentes características e marcas comerciais
}

\author{
Bitterness Unit and iso-alfa-acids contents of some brands of Brazilian and North American beers
}

Paulo Henrique Alves da SILVA ${ }^{1 \star}$, Fernanda Carolina de FARIA ${ }^{1}$

\section{Resumo}

Os principais compostos responsáveis pelo amargor de cervejas são os iso- $\alpha$-ácidos provenientes do lúpulo, que participam de maneira importante no sabor da bebida. Procurou-se, neste trabalho, diferenciar algumas cervejas brasileiras líderes do mercado nacional em relação a algumas marcas disponíveis no mercado do oeste dos Estados Unidos, compreendendo cervejas tipo lager, ale e de microcervejarias. Discutese a relação entre unidades de amargor $(\mathrm{BU})$ e os teores de iso- $\alpha$-ácidos totais e suas frações isohumulona, isocohumulona e isoadhumulona presentes nestes tipos de cerveja. Os resultados mostraram que a cerveja do tipo Indian Pale Ale apresentou maior nível de BU, apesar da concentração de iso- $\alpha$-ácidos totais aproximar-se dos valores de cervejas lager e de microcervejaria. Cervejas tipo lager norte-americanas apresentaram as menores intensidades de amargor, seguidas das marcas brasileiras (de 11 a 15 BU). Com relação às frações dos iso- $\alpha$-ácidos, destaca-se que a isoadhumulona foi a fração de concentração mais baixa em todas as amostras e que na maioria das amostras prevalecem concentrações superiores de isohumulona. A faixa de concentração de isohumulonas permaneceu entre 3,0 e 17,0 mg. $\mathrm{L}^{-1}$.

Palavras-chave: cerveja; amargor; lúpulo; iso- $\alpha$-ácidos; Bitterness Units.

\begin{abstract}
Iso- $\alpha$-acids is a group of compounds which have an important participation in beer flavor. They are responsible for the bitterness which is provided by the hops used during brewing. This study was conducted in order to characterize some Brazilian and North American beers according to bitter characteristics, as Bitterness Units (BU), through the use of a spectrophotometric method or as total iso- $\alpha$-acids and their isohumulone, isocohumulone, and isoadhumulone fractions by HPLC. Most of the beers evaluated were lager pilsener coming from market leader industries, ale and others produced in microbrewing plants. The Indian Pale Ale beer type, produced by late hopped process, showed the highest BU although the iso- $\alpha$-acids content in this brand were not as higher as the BU compared to the other samples. North American lager beers presented lower intensities of bitter taste followed by the Brazilian brands (11-15 BU). With regards to the fractions of iso- $\alpha$-acids, it is distinguished that isoadhumulona was the fraction of lower concentration in all the samples, and the majority of the samples showed higher concentration of isohumulona. The range of isohumulona was between 3,0 and 17,0 mg.L-1.
\end{abstract}

Keywords: beer; bitterness; hop; iso- $\alpha$-acids; Bitterness Units.

\section{Introdução}

A produção e o consumo de cervejas no Brasil são caracterizados pela presença de poucas marcas de quase que um único tipo de cerveja, do tipo lager pilsener, sendo que outros tipos apresentam um consumo restrito, principalmente por consumidores mais exigentes em termos de qualidade sensorial, que buscam um produto diferenciado, independentemente do preço. A baixa diversidade de produtos de cervejaria brasileira contrasta com o modelo de outros países, onde se observa uma grande variedade de marcas e tipos de cervejas, com sabores, coloração e amargor distintos.

Cervejas são classificadas basicamente em dois tipos: lager (de baixa fermentação) e ale (de alta fermentação). Cervejas do tipo lager são fermentadas à temperatura de 3,3 a $13{ }^{\circ} \mathrm{C}$ e a duração da fermentação e da maturação pode ser de 4 a 12 semanas (ARAÚJO; SILVA; MINIM, 2003). Devido às baixas temperaturas usadas no processo, os sabores e aromas das cervejas lager são mais suaves e leves em comparação com as ales
(HARDWICK, 1995). As cervejas do tipo lager, que são elaboradas com cepas de Saccharomyces calsbergensis, são mais populares mundialmente e as do tipo "ale", elaboradas com cepas de Saccharomyces cerevisae, são muito populares na Grã Bretanha (TIPOS DE CERVEJAS, 2007; VARNAM; SUTHERLAND, 1997). Embora exista esta diferenciação tecnológica no setor de cervejarias, geralmente as espécies de leveduras cervejeiras são citadas como Saccharomyces cerevisiae, sendo que outras classificações são utilizadas para agrupar diferentes espécies e linhagens de Saccharomyces (ANDRIETTA; MIGLIARI; ANDRIETTA, 1999; VAUGHAN-MARTINI; MARTINI, 1993).

Já a cerveja de microcervejaria caracteriza-se por ser um produto mais encorpado e de aroma e sabor mais pronunciados que as demais. Estas características, provenientes, dentre outros fatores, da utilização de variedades específicas de lúpulo, justificam o crescimento acentuado deste segmento (KEUKELEIRE, 2000). Nos Estados Unidos, entendem-se, como microcervejaria, todas

Recebido para publicação em 12/7/2007

Aceito para publicação em 16/3/2008 (002676)

${ }^{1}$ Laboratório de Produção e Qualidade de Bebidas, Departamento de Tecnologia de Alimentos, Universidade Federal de Viçosa - UFV, CEP 36570-000, Viçosa - MG, Brasil, E-mail:phasilva@ufv.br

${ }^{*}$ A quem a correspondência deve ser enviada 
as empresas que produzem até 15 mil barris por ano, equivalendo um barril a 3,78 litros (NEVES, 1996).

A cerveja possui diversos compostos de odor e sabor (HOUGH et al., 1982; VERHAGEN, 1999). Alguns deles são provenientes das matérias-primas malte e lúpulo, sendo, grande parte, formada durante o processo de brassagem, que consiste de diversas etapas, incluindo-se a fermentação, de particular importância. O lúpulo (Humulus lupulus,L.), adicionado ao final da etapa de mosturação, sob a forma de pellets ou essências, é o responsável pelo sabor amargo da cerveja (HUGHES; SIMPSON, 1993; SANDRA, 1976). Processos tecnológicos mais modernos para extração do princípio ativo amargo utilizam $\mathrm{CO}_{2}$ supercrítico.

Os compostos ativos de aroma de lúpulo estão presentes nas glândulas das flores fêmeas da planta (Figura 1) e estas geralmente apresentam de 4 a $5 \mathrm{~cm}$ de comprimento. O lúpulo constituise de óleos essenciais (0,2-3\%), $\beta$-ácidos, também chamados lupulonas $(1,5-9,5 \%)$ e de $\propto$-ácidos (2,0-16,0\%) (NOONAN, 1996), também chamados humulonas. As proporções de cada composto dependem da variedade da planta.

Os óleos essenciais do lúpulo possuem composição bastante complexa, apresentando mais de 200 compostos (SHARP; LAWS, 1981) e contribuem para o sabor diferenciado das cervejas produzidas pelo processo de adição tardia de lúpulo (late hopped beer) (ELVIDGE; JONES, 1985; KRALJ; ZUPANEC, 1991; TRESSL et al., 1978).

Os $\beta$-ácidos contribuem em menor intensidade para o amargor (TECHAKRIENGKRAIL et al., 2004). Eles possuem ação bactericida, agindo no transporte de metabólitos na membrana celular e alterando o $\mathrm{pH}$ intracelular (SIMPSON; SMITH, 1992). Já uma pronunciada ação bacteriostática sobre bactérias Gram-positivas parece estar relacionada à interferência do grupo prenil, presente nas cadeias laterais dos $\beta$-ácidos, sobre a membrana plasmática das células, inibindo fortemente o seu crescimento (KEUKELEIRE, 2000).

Os $\alpha$-ácidos são isomerizados através de calor produzindo os iso- $\alpha$-ácidos, que são constituídos principalmente por isohumulona, isocohumulona e isoadhumulona. Em vários trabalhos, os iso- $\alpha$-ácidos têm sido relacionados com a intensidade do

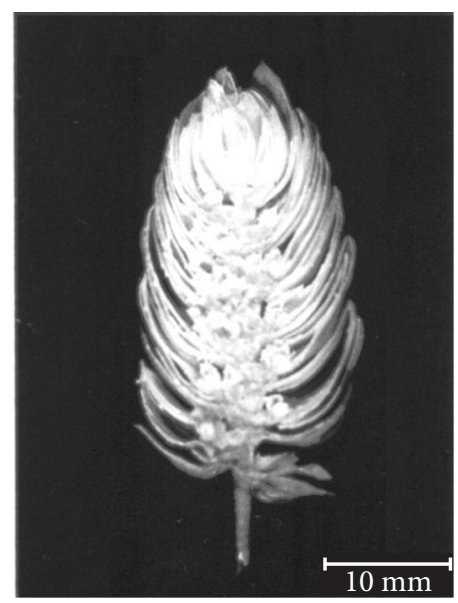

Figura 1. Corte longitudinal das flores fêmeas de lúpulo, observando-se no interior as glândulas que contêm os iso- $\alpha$-ácidos. amargor em cervejas (HUGHES, 2000; HUGHES; SIMPSON, 1996; KEUKELEIRE, 2000; KING; DUINEVELD, 1999; TECHAKRIENGKRAIL et al., 2004). Estes são considerados mais amargos que os ácidos originais não isomerizados, sendo responsáveis por mais de $70 \%$ do amargor detectado sensorialmente em cerveja (TECHAKRIENGKRAIL et al., 2004).

A estrutura geral dos iso- $\alpha$-ácidos e de seus derivados é representada na Figura 2. As estruturas iso correspondem às formas isomerizadas cis e trans dos seus respectivos precursores não isomerizados. Mesmo estas frações têm efeito diferenciado sobre o amargor. Isohumulona é o composto cuja estrutura geral tem como radical $\mathrm{R}$ um grupamento 2-metilpropil, sendo que os compostos isoadhumulona e isocohumulona têm como radical os grupamentos 1-metilpropil e 1-metil etil, respectivamente.

O método padrão para se estimar o amargor de cervejas utiliza a medida dos iso- $\alpha$-ácidos totais por técnicas espectrofotométricas, após sua extração por solventes, expressando sua concentração em Bitterness Units (BU). Convenções européias e norte-americanas adotam esta técnica como oficial. A precisão e a conveniência de utilização foram analisadas recentemente (PHILPOTT; TAYLOR; WILLIAMS, 1997). Acredita-se que as medidas obtidas por este método têm boa correlação com as percepções humanas do amargor em cervejas do tipo ale e lager (TECHAKRIENGKRAIL et al., 2004).

Este trabalho foi realizado com o objetivo de se medir analiticamente as características amargas de algumas marcas de cervejas brasileiras e americanas, determinando-se o amargor em termos de BU, por método espectrofotométrico, bem como a quantificação por cromatografia líquida de frações específicas dos iso- $\alpha$-ácidos presentes nas amostras por cromatografia líquida.

\section{Material e métodos}

\subsection{Materiais experimentais utilizados}

Dentre as amostras de cerveja analisadas, quatro são de marcas brasileiras líderes de mercado e oito são de marcas disponíveis predominantemente no mercado da região oeste dos Estados Unidos. Esse local é tradicional por produzir cervejas diferenciadas em termos de sabor e em escala de produção, sendo o segmento de microcervejarias fortemente implantado nessa região. Estas amostras foram coletadas em alguns pontos de distribuição de bebidas, coletadas em duplicata, e analisadas em triplicata. Nesta amostragem foram incluídas cervejas tipo lager, ale, Indian Pale Ale (lupulagem tardia) e também produzidas em microcervejarias, compreendendo as marcas americanas Beck, Bridget Indian Pale Ale, Corona, Honeybeer, Pyramid, Michelob, Samuel Adams Golden Pilsen e Boston Lager, e as brasileiras Antarctica, Brahma, Kaiser e Skol. A origem e o tipo de cervejas amostradas estão relacionados na Tabela 1.

\subsection{Métodos}

\section{Determinação de unidades de amargor (BU)}

A análise global de amargor, normalmente expressa como Bitterness Units, foi determinada após extração por isooctano 


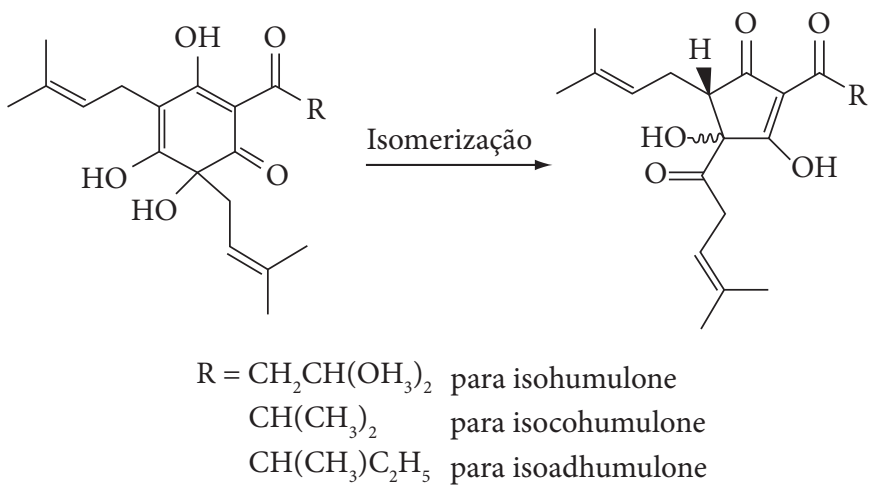

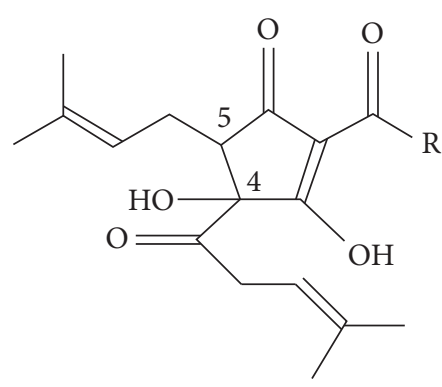

Trans-isocohumulone

Trans-isohumulone

Trans-isoadhumulone

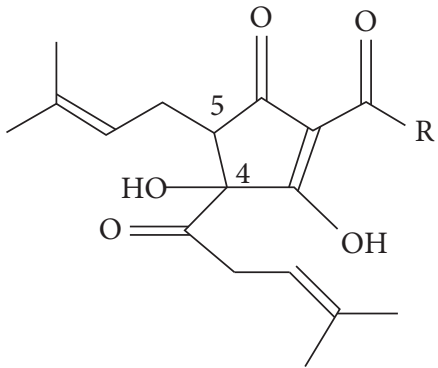

Cis-isocohumulone

Cis-isohumulone

Cis-isoadhumulone

Figura 2. Isomerização de $\alpha$-ácidos em iso- $\alpha$-ácidos e seus derivados.

Tabela 1. Classificação das amostras analisadas quanto ao amargor.

\begin{tabular}{ccc}
\hline Cerveja & Origem & Tipo \\
\hline 1 & Norte-americana & Indian Pale Ale \\
2 & Norte-americana & Lager \\
3 & Norte-americana & Microcervejaria \\
4 & Norte-americana & Lager \\
5 & Norte-americana & Pale Ale \\
6 & Brasileira & Lager Pilsener \\
7 & Brasileira & Lager Pilsener \\
8 & Brasileira & Lager Pilsener \\
9 & Brasileira & Lager Pilsener \\
10 & Norte-americana & Lager \\
11 & Norte-americana & Lager \\
12 & Norte-americana & Lager \\
\hline
\end{tabular}

(2,2,4-trimetilpentano) em amostras acidificadas, seguido de medição espectrofotométrica em comprimento de onda de $275 \mathrm{~nm}$, utilizando-se metodologia descrita por Philpott, Taylor e Williams (1997). Este método apresenta algumas limitações com relação à real identificação destes compostos diretamente relacionados ao amargor, sendo recomendadas análises específicas, como HPLC (SCHÖNBERGER, 2007).

\section{Análise de frações iso alfa-ácidos}

Os compostos foram analisados por cromatografia líquida, utilizando-se coluna Nucleosil C18, partículas de $5 \mu \mathrm{e}$ dimensões de $15 \mathrm{~cm} \times 0,45 \mathrm{~cm}$, detectando-se os iso- $\alpha$-ácidos a $280 \mathrm{~nm}$, com sistema de solventes constituído de etanol, água e ácido acético. Estas amostras foram submetidas previamente à extração dos iso- $\alpha$-ácidos, utilizando-se Extração em Fase Sólida (Solid Phase Extraction - SPE), com acondicionamento do filtro com metanol e posteriores lavagens da amostra com água antes da eluição dos iso- $\alpha$-ácidos.

\section{Resultados e discussão}

Os resultados das análises são apresentados na Figura 3. A cerveja 1, do tipo Indian Pale Ale (IPA), apresentou valor de BU bastante elevado em relação aos demais tipos. Os valores de amargor das demais marcas situaram-se entre 12 e 27 BU, sendo que a cerveja menos amarga, utilizando este método, foi a cerveja 8 (brasileira tipo pilsener). Estes resultados confirmam a tendência apontada por Schönberger (2007), que ressaltou que a faixa de unidade de amargor em cervejas, que geralmente se situavam entre 20 e $50 \mathrm{BU}$, atualmente encontra-se entre 10 e 25 BU. Esta tendência pode ser justificada pelos resultados obtidos de painéis sensoriais realizados com provadores treinados em relação à preferência do teor de amargor em cerveja. Segundo Collin et al. (1994), a faixa de unidades de amargor na qual as cervejas foram preferidas foi de 17,5 a $25 \mathrm{BU}$, valores estes próximos aos encontrados neste trabalho.

As cervejas nacionais $(6,7,8$ e 9$)$ apresentaram concentrações de iso- $\alpha$-ácidos variando de 13 a 20 mg. $\mathrm{L}^{-1}$, ligeiramente 
maiores que as cervejas norte-americanas tipo lager (10, 11 e 12), cujos valores aproximaram-se de $10 \mathrm{mg} \cdot \mathrm{L}^{-1}$.

Apesar da grande diferença de amargor da cerveja 1, em termos de BU, quando se observa a concentração de iso- $\alpha$-ácidos em relação às demais marcas, não há uma discrepância tão elevada. Percebe-se pela Figura 3 que a cerveja 1 (IPA) e a cerveja 3, de microcervejaria, apresentaram resultados semelhantes, de aproximadamente $31 \mathrm{mg} . \mathrm{L}^{-1}$ de iso- $\alpha$-ácidos totais.

Alguns autores sugerem que o teor de etanol e o retrogosto das cervejas podem afetar a percepção do amargor (HUGHES; SIMPSON, 1996; SCHÖNBERGER, 2007). Além disto, para uma mesma concentração de iso- $\alpha$-ácidos, o amargor pode ser diferente para cada bebida, dependendo da concentração dos isômeros cis e trans. Estes contribuem em proporções diferentes no amargor da cerveja e sua formação depende das condições de isomerização dos iso- $\alpha$-ácidos ${ }^{13}$, ocorrida durante a fermentação do mosto (TECHAKRIENGKRAIL, 2004). Provavelmente, a cerveja 1 possui baixa concentração dos isômeros trans em relação aos cis, que são significativamente mais amargos que os primeiros (SCHÖNBERGER, 2007).

A distribuição das três frações nas diferentes marcas de cerveja é variável (Figura 4), destacando-se a isoadhumulona como a fração de concentração mais baixa em todas as amostras. A cerveja 3, de microcervejaria, foi a que apresentou a maior concentração desta fração; entretanto, a participação desta no amargor da cerveja não é comumente estudada nem citada na literatura.

A relação isohumulona/isocohumulona não é diretamente proporcional e padronizada para as diferentes amostras analisadas. Em alguns casos elas se aproximam de 1,0, prevalecendo na maioria das amostras concentrações superiores de isohumulona.

Segundo Guinard et al. (1996), o teor de isohumulonas em cervejas norte-americanas tipo lager varia de 12 a $17 \mathrm{mg} . \mathrm{L}^{-1}$, superiores, portanto, aos resultados encontrados neste trabalho. Para estas cervejas, a fração de isohumulona apresentou concentração na faixa de 3 a 6 mg.. $\mathrm{L}^{-1}$, com exceção da cerveja 2 ( $12 \mathrm{mg}$. $\left.\mathrm{L}^{-1}\right)$. Já os resultados encontrados para as cervejas do tipo IPA, microcervejaria e Pale Ale (13, 17 e $12 \mathrm{mg} . \mathrm{L}^{-1}$, respectivamente) se aproximaram da faixa de concentração citada por estes autores. Em relação às

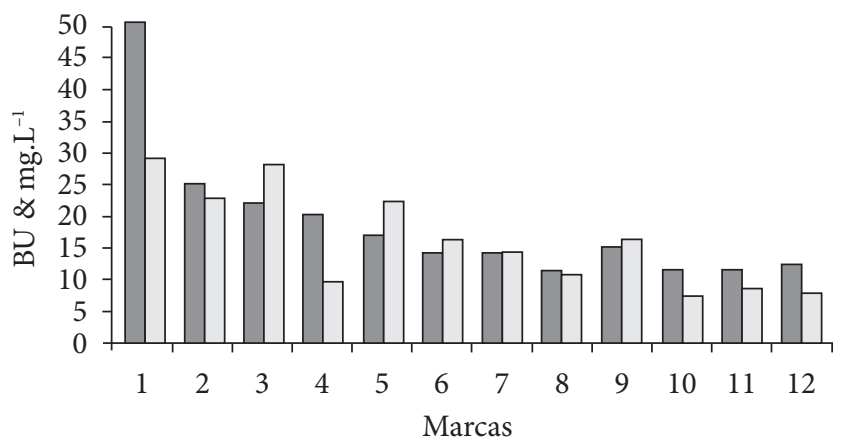

Unidades de amargor (BU)

Iso-alfa ácidos totais (mg. $\mathrm{L}^{-1}$ )

Figura 3. Unidades de amargor (BU) e concentração de iso- $\alpha$-ácidos totais em cerveja. doze amostras analisadas, verifica-se que a faixa de concentração de isohumulonas permaneceu entre 3,0 e 17,0 mg.L.-1.

Para a isocohumulona, a concentração mais elevada foi verificada para a cerveja 1, do tipo IPA, seguida das cervejas 2 e 3 . Esta fração tem sido associada à baixa qualidade do lúpulo, de sabor indesejável, embora estas evidências sejam contestadas (KEUKELEIRE, 2000; WACKERBAUER; BALZER, 1992).

Em relação à contribuição no amargor da cerveja, vários estudos ordenam a intensidade deste atributo de acordo com as frações de iso- $\alpha$-ácidos, considerando-se também os isômeros cis e trans de cada fração. Como regra geral, isohumulonas são mais amargas que isocohumulonas e os isômeros cis mais amargos que os trans (HUGHES; SIMPSON, 1996; KING; DUINEVELD, 1999; SCHÖNBERGER, 2007). Desta forma, a intensidade de amargor pode ser ordenada da seguinte forma: cis-isohumulona $>$ trans-isohumulona $>$ cis-isocohumulona $>$ trans-isocohumulona.

Relacionando estas informações e os resultados demonstrados nas Figuras 3 e 4, sugere-se que as baixas concentrações de isohumulona das cervejas norte-americanas tipo lager $(4,10,11$ e 12$)$ e das brasileiras $(6,7,8$ e 9$)$ possam ter levado a baixos valores de $\mathrm{BU}$, detectados por espectrofotometria.

Já a cerveja de microcervejaria apresentou o maior teor desta fração e unidades de amargor inferior a da cerveja tipo IPA. Como discutido anteriormente, provavelmente há diferenças entre as relações de isômeros cis:trans destes tipos de cerveja e que esta taxa para a cerveja IPA seja mais alta que para o outro tipo de cerveja.

\section{Conclusões}

Os métodos espectrofotométrico e cromatográfico apresentaram resultados semelhantes para as cervejas tipo lager pilsener, provenientes dos mercados brasileiro e norte-americano.

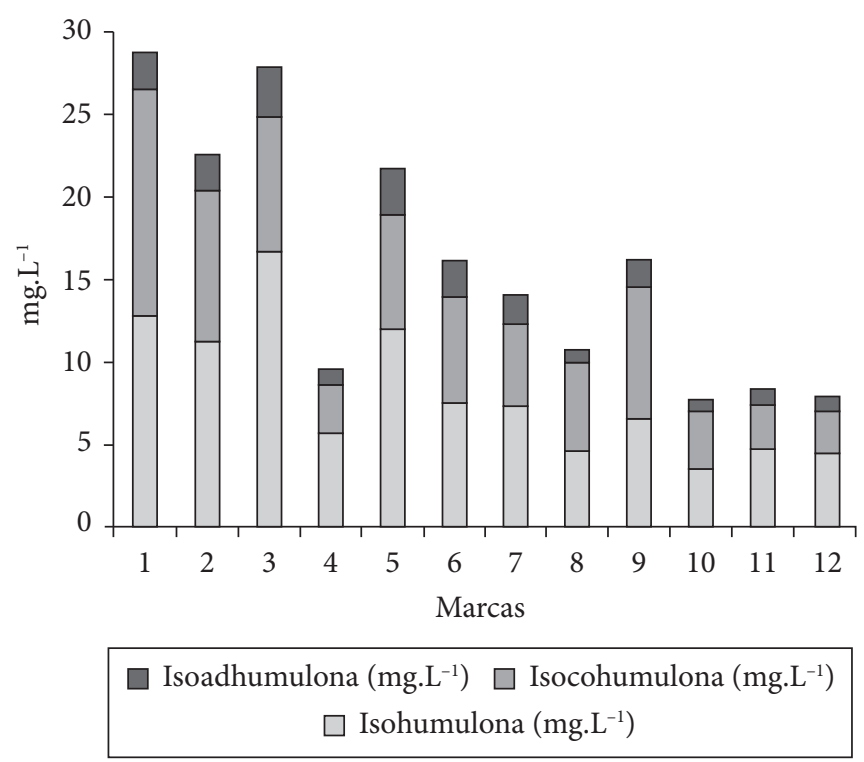

Figura 4. Concentração de isoadmulona, isocohumulona e isohumulona, em mg. $L^{-1}$, em cervejas. 
Entretanto, concentrações de iso- $\propto$-ácidos semelhantes das cervejas tipo Indian Pale Ale e de microcervejaria não equivaleram às intensidades de amargor obtidas, já que a primeira delas apresentou valor de BU bastante elevado em relação às demais marcas.

A participação das diferentes frações iso- $\propto$-ácidos é caracterizada por baixas concentrações de isoadhumulona e concentrações mais elevadas e próximas de isocohumulona e isohumulona, que é a fração mais amarga do lúpulo.

A ligação entre a percepção do amargor e os componentes de sabor das cervejas ainda não é muito clara. Sugere-se, assim, que sejam estudadas frações ainda mais específicas dos compostos de amargor, como a determinação das concentrações dos isômeros cis e trans dos iso- $\propto$-ácidos, relacionando-as com a intensidade de amargor em termos de BU, tanto através de método espectrofotométrico quanto por painéis sensoriais. Além disto, as interferências do etanol e de retrogostos de compostos das cervejas na percepção do amargor devem ser pesquisados, na tentativa de elucidar a relação existente entre a composição da cerveja e a intensidade deste gosto.

\section{Agradecimentos}

À CAPES/MEC pela concessão de bolsa de estudos ao primeiro autor.

\section{Referências bibliográficas}

ANDRIETTA, S. R.; MIGLIARI, P. C.; ANDRIETTA, M. G. S. Classificação das cepas de levedura de processos industriais de fermentação alcoólica utilizando capacidade fermentativa. STAB: Açúcar, Álcool e Subprodutos, v. 17, n. 5, p. 54-59, 1999.

ARAÚJO, F. B.; SILVA, P. H. A.; MINIM, V. P. R. Perfil sensorial e composição físico-química de cervejas provenientes de dois segmentos do mercado brasileiro. Ciência e Tecnologia de Alimentos, v. 23, n. 2, p. 121-128, 2003.

BRASIL. Decreto n. 2314, de 04 de setembro de 1997. Regulamenta a Lei n 8.918, de 14 de julho de 1994, que dispõe sobre a padronização, a classificação, o registro, a inspeção, a produção e a fiscalização de bebidas. Diário Oficial da União, DF, 05 set. 1997.

COLLIN, S.; DERDELINCKX, G..; DUFOUR, J. P. Relationships between the chemical composition and sensory evaluation of lager beers. Food Quality and Preference, v. 5, n. 1-2, p. 145-149, 1994.

ELVIDGE, J. A.; JONES, S. P. Non-implication of hop $\propto$ - and $\beta$-acids as sources of sulphur compounds in beer. Journal of the Institut of Brewing, v. 91, n. 1, p. 34-36, 1985.

GUINARD, J. X. et al. Does consuption of beer, alcohol and bitter substances affect bitteness perception? Physiology and Behavior, v. 59, n. 4 , p. 625-631, 1996.

HARDWICK, W. A. Handbook of brewing. New York: Dekker, 1995. $713 p$.

HOUGH, J. S. et al. Malting and brewing science. Cambridge: University Press. v. 2, 1982. 400p.
HUGHES, P. The significance of iso-alfa-acids for beer quality cambridge prize paper. Journal of the Institut of Brewing, v. 106, n. 5, p. 271-276, 2000.

HUGHES, P. S.; SIMPSON, W. J. Bitterness of congeners and stereoisomers of hop-derived bitter acids found in beer. Journal of American Society of Brewing Chemists, v. 54, n. 4, p. 234-237, 1996.

HUGHES, P. S.; SIMPSON, W. J. Production and composition of hop products. MBAA Technical Quarterly, v. 30, n. 4 , p. 146-154, 1993.

KEUKELEIRE, D. Fundamentals of beer and hop chemistry. Química Nova, v. 23, n. 1, p. 108-112, 2000.

KING, B. M.; DUINEVELD, C. A. A. Changes in bitterness as beer ages naturally. Food Quality and Preference, v. 10, n. 4, p. 315-324, 1999.

KRALJ, D.; ZUPANEC, J. Variability of essential oils of hops, Humulus lupulus L. Journal of the Institut of Brewing, v. 97, p. 197-206, 1991.

NEVES, A. L. R. A. Viabilidade técnico-econômica e análise de risco da implantação de microcervejarias no Brasil. Viçosa, 1996. 79p. Dissertação - (Mestre em Ciência e Tecnologia de Alimentos), Universidade Federal de Viçosa - UFV.

NOONAN, G. J. New brewing lager beer. Boulder: Brewers Publications, 1996. 363p.

PHILPOTT, J.; TAYLOR, D. M.; WILLIAMS, D. R. Critical assessment of factors affecting the accuracy of the IoB Bitterness Method. Journal of American Society of Brewing Chemists. v. 55, n. 3, p. 103-106, 1997.

SANDRA, P. La contribution du houblon au gout et a l'arome de la biere. Cerevisiae, v. 1, p. 37-44, 1976.

SCHÖNBERGER, C. Bitter is better - a review on the knowledge about bitterness in beer. Disponível em: $<\mathrm{https} / / \mathrm{my}$.johnihaas.com/ $\mathrm{cmsdk} /$ content/bhg/research/pdf/06_bitterisbetter_Schoenbe_MfB. pdf>. Acesso em: 10 jun. 2007.

SHARP, F. R.; LAWS, D. R. J. The essential oil of hops - a review. Journal of the Institut of Brewing, v. 87, p. 96-107, 1981.

SIMPSON, W. J.; SMITH, A. R. W. Factors affecting antibacterial activity of hops compounds and their derivatives. Journal of Applied Bacteriology, v. 72, n. 4, p. 327-334, 1992.

TECHAKRIENGKRAIL, I. et al. Relationships of sensory bitterness in lager beers to iso-alfa-acid contents. Journal of the Institut of Brewing, v. 110, n. 1, p. 51-56, 2004.

TRESSL, R. et al. Gas chromatographic-mass spectrometric investigation of hop aroma constituents in beer. Journal of Agricultural and Food Chemistry, v. 26, n. 6, p. 1422-1430, 1978.

TIPOS DE CERVEJAS. Disponível em: <http//www.montana.com. br>. Acesso em: 5 jun. 2007.

VARNAM, A. H.; SUTHERLAND, J. P. Bebidas. Espanha: Acribia, 1997. 487p.

VAUGHAN-MARTINI, A.; MARTINI, A. A taxonomic key for the genus Saccharomyces. Systematic and Applied Microbiology, v. 16, n. 1, p. 113-119, 1993.

VERHAGEN, L. C. Beer flavour. In: PIGGOTT, J. R.; PATERSON, A. Understanding natural flavors. London: Blakie Academic \& Professional, 1999. 318p.

WACKERBAUER, K.; BALZER, U. Hop bitter compounds in beer; Part II: The influence of cohumulone on beer quality. Brauwelt International II, p. 116-118, 1992. 